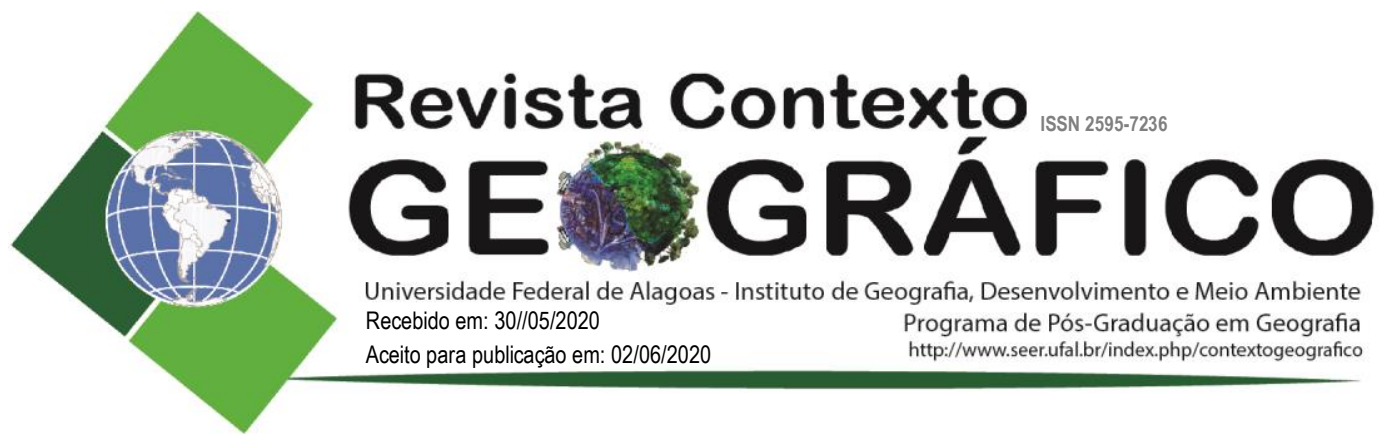

\title{
OS NOVOS USOS DO TERRITÓRIO PELO AGRONEGÓCIO FLORESTAL NA MICRORREGIÃO DE IMPERATRIZ, MARANHÃO
}

\author{
Allison Bezerra Oliveira \\ Professor da Universidade Estadual da Região Tocantina do Maranhão - UEMASUL, MA, Brasil \\ allisonbzr@gmail.com
}

Karolayne Carneiro dos Santos

Graduanda em Geografia da Universidade Estadual da Região Tocantina do Maranhão -

UEMASUL, MA, Brasil

karolaynecarneiro.kc@gmail.com

Amanda Miranda Pereira

Graduanda em Engenharia Florestal da Universidade Estadual da Região Tocantina do Maranhão - UEMASUL, MA, Brasil, MA, Brasil

amandamirandh@gmail.com

\begin{abstract}
RESUMO - Este artigo tem como objetivo analisar as transformações na produção de culturas agrícolas tradicionais em municípios no sul da microrregião de Imperatriz, no estado do Maranhão, frente os novos usos no território provocados pelo agronegócio florestal, neste caso, a silvicultura do eucalipto. O recorte da pesquisa compreende os municípios de Davinópolis, Governador Edison Lobão e Ribamar Fiquene, e as culturas de arroz, feijão e mandioca. Discute as transformações no uso da terra, geradas pela transição para a cultura do eucalipto e consequente especialização produtiva de pequenos territórios para atender à etapa de produção de matéria-prima da cadeia produtiva de papel e celulose no estado. Metodologicamente, além de visitas de campo, entrevistas, produção fotográfica e cartográfica, foram utilizados dados secundários do Instituto Brasileiro de Geografia e Estatística e da Indústria Brasileira de Árvores. Os resultados obtidos indicam que a rápida expansão da silvicultura do eucalipto tem promovido, além da concentração fundiária, a diminuição da produção de culturas de subsistência tradicionais nesses municípios.
\end{abstract}

Palavras-chave: Agricultura familiar; silvicultura do eucalipto; Maranhão.

\section{HE NEW USES OF THE TERRITORY BY FOREST AGRIBUSINESS IN THE MICRO-REGION OF IMPERATRIZ, MARANHÃO}

\begin{abstract}
This article aims to analyze the transformations in the production of traditional agricultural crops in municipalities in the south of the micro region of Imperatriz, in the state of Maranhão, in view of the new uses in the territory caused by forestry agribusiness, in this case, eucalyptus silviculture. Such cut includes the municipalities of Davinópolis, Governor Edison Lobão and Ribamar Fiquene and the rice, beans and cassava crops. It discusses the transformations in land use in these municipalities, generated by the transition to eucalyptus cultivation and the consequent productive specialization of small territories to meet the stage of production of raw material in the paper and cellulose production chain in the state. Methodologically, in addition to field visits, interviews, photographic and cartographic production, secondary data from the Brazilian Institute of Geography and Statistics were used. The results obtained indicate that the rapid expansion of eucalyptus silviculture has promoted, in addition to land concentration, a decrease in the production of traditional subsistence crops in these municipalities.
\end{abstract}

Keywords: Family farming; eucalyptus forestry; Maranhão. 


\section{INTRODUÇÃO}

No Maranhão, o processo de inserção da silvicultura de eucalipto está vinculado à implantação do Projeto Carajás, no Pará, e à consequente construção do complexo industrial produtor de ferro-gusa, no município maranhense de Açailândia. O eucalipto, nesse contexto, teve uso na produção de carvão, como fonte de energia para as caldeiras industriais. Já na década de 1990, intensificou-se a aquisição de áreas para plantio com vistas a subsidiar a Companhia de Celulose do Maranhão (Celmar), um então recente projeto de indústria de celulose no estado.

Nesse cenário, a implantação do Grande Projeto Suzano Papel e Celulose, no município de Imperatriz, em 2008, intensificou o avanço do eucalipto em áreas vizinhas e tradicionalmente destinadas à produção de alimentos básicos (arroz, feijão e mandioca), sobretudo áreas de agricultura de subsistência e pequenas propriedades agrícolas. Desde então, isso vem alterando a estrutura produtiva local devido a essa reconfiguração do território.

Assim, o objetivo deste trabalho é analisar as transformações na produção de culturas agrícolas tradicionais em três municípios no sul da microrregião de Imperatriz, no estado do Maranhão, frente os novos usos do território provocados pelo agronegócio florestal, neste caso, a silvicultura do eucalipto.

Partimos da hipótese de que o aumento da compra e do arrendamento de terras para o plantio de eucalipto, juntamente com outros problemas estruturais históricos, têm acarretado a diminuição das áreas destinadas às culturas regionais mais tradicionais, logo, da produção de alimentares.

Metodologicamente, o recorte de análise compreende as culturas de arroz, feijão e mandioca nos municípios de Davinópolis, Governador Edison Lobão e Ribamar Fiquene. Foram realizadas pesquisas de campo para registros fotográficos e para subsidiar a produção cartográfica. Também foram feitas entrevistas com moradores, além de coleta de dados secundários do Instituto Brasileiro de Geografia e Estatística (IBGE) e da Indústria Brasileira de Árvores (IBÁ).

Além desta introdução e das considerações finais, o trabalho está dividido em três tópicos principais. O primeiro, Território e agricultura familiar, discute a importância do território para a constituição da agricultura familiar; em seguida, discute-se a expansão da silvicultura do eucalipto no Maranhão e o uso do território por essa cultura. Por fim, são abordadas as transformações das atividades agrícolas tradicionais em municípios maranhenses estudados.

\section{TERRITÓRIO E AGRICULTURA FAMILIAR}

A formação do espaço maranhense está diretamente atrelada a ciclos econômicos fortemente fincados no setor primário e relacionados ao uso da terra. Ao longo dos anos, esses ciclos subsidiaram a emergência de modelos de crescimento baseados principalmente na exploração e na pilhagem de recursos naturais, além de outros fatores, como concentração fundiária e conflitos territoriais de diversas ordens (OLIVEIRA, 2019).

A estrutura agrária maranhense é marcada pelo grande latifúndio desde o período colonial, quando a concessão de terras constituía uma tradicional prática da Coroa portuguesa: a distribuição de sesmarias. Além disso, a ação de posseiros também teve grande participação nessa primeira onda de ocupação da terra. Em ambos os casos, subjaziam as ideias de desenvolver a produção agrícola e ocupar o território. Dessa forma, o desenvolvimento territorial do estado sempre esteve ligado à produção de gêneros alimentares básicos de subsistência, por exemplo: cana-de-açúcar, algodão, arroz, tabaco e "frutos da terra" (cacau, anil, cravo-de-casca); tendo como características também a prática de monocultura, o latifúndio e o uso de mão de obra escravizada (CHAMBOULEYRON, 2010; AZEVEDO, 2003).

Apesar da predominância do latifúndio no território maranhense, as dimensões geográficas do 
estado e os fluxos de migração e mobilidade interna possibilitaram que se constituísse uma expressiva base agrícola familiar. Dadas as históricas limitações de desenvolvimento tecnológico e industrial da região, esse cenário mantém a configuração similar até os dias atuais. Desta forma, a agricultura familiar, além de outras formas de trabalho coordenado por famílias, como o extrativismo (principalmente de amêndoas) e a criação de pequenos animais, constituem importante base econômica do estado.

A agricultura familiar é um processo socioeconômico caracterizado pela relação entre terra, trabalho e família. Nesse tipo de agricultura, o cultivo da terra é realizado por famílias que tanto detêm os meios de produção quanto são responsáveis pelo trabalho produtivo. A relação com a propriedade é um traço marcante na agricultura familiar, uma vez que a noção de propriedade, posse, identidade e o sentimento de pertencimento ao território são bastante presentes nesses núcleos familiares de produtores rurais (SILVA, 2011; SILVA; MENDES, 2010).

Em suma, a agricultura familiar pode ser descrita como toda forma de cultivo de terra que é administrada por uma família e emprega seus membros como mão de obra. A produção de alimentos e a pequena produção animal acontecem em pequenas propriedades de terra e se destinam à subsistência do produtor rural e ao mercado interno do país. Propriedade da terra e dos meios de produção, divisão de trabalho familiar, além de forte pertencimento ao território, são elementos fundamentais nessa estrutura socioeconômica.

A construção do território se dá em função do seu uso, fator que também condiciona o valor que lhe é atribuído. Nesse sentido, o território é importante para reprodução da unidade familiar, sendo o elo fundamental da família com o meio rural. Como categoria-chave na construção da identidade da agricultura familiar, o território deve ser entendido como um lugar de relações sociais, relações de poder e de vida; um lugar de produção econômica e de mudanças, dotado de identidade. Além disso, é a manifestação individual e coletiva de um estado; produto socioespacial e condição para o habitar, o viver e o produzir (SILVA, 2010; SAQUET, 2007).

Haesbaert (1997, 2012) defende o território como uma apropriação simbólica, social, cultural, política e identitária, relacionado a determinado grupo no espaço. Para o autor, trata-se de uma categoria geográfica que diz respeito à apropriação, em seu sentido mais simbólico, ligada a qualquer atividade territorialmente estabelecida. Sendo assim, o território além de assumir um caráter político e econômico, deve ser considerado a partir de suas múltiplas dimensões. Ele é a base das trocas materiais e imateriais de determinados grupos sociais e deve ser compreendido sempre a partir do seu uso, como o uso familiar para a agricultura.

O território deve, portanto, ser entendido como o espaço onde acontecem as relações sociais, como a cultura, os costumes, a religião, o sistema de produção, a organização política e econômica. Nesse sentido, o território pertencente aos agricultores familiares não é apenas um local onde residem grupos sociais, e sim também um espaço cultural, identitário, onde se desenvolvem relações de afetividade que refletem contextos distintos, construídos ao longo do tempo. Para esse segmento, o território é o espaço de se viver e produzir, é onde estão seus vínculos emocionais relacionados com o espaço ocupado e que permeiam todas as relações de produção e reprodução (SILVA, 2011).

Dessa forma, a construção de identidade dos agricultores familiares, bem como do território, pode ser considerada temporal e mutável, uma vez que identidades se transformam ao longo do tempo, tendo em vista que os modos de vida dos grupos sociais estão em constante transformação, sobretudo no que se refere a práticas sociais, políticas e econômicas (SILVA; MENDES, 2010).

Por ser uma demarcação política fruto da ação de pequenos grupos fortemente vinculados à terra, os territórios de agricultura familiar destacam-se por sua fragilidade ante o capital monopolista dos grandes atores hegemônicos globais. Nesse cenário, o agronegócio, ao intensificar a produção de commodities para o mercado externo, coloca-se como o principal agente direto da fragmentação e reestruturação desses pequenos territórios no país. 
OLIVEIRA, A. B.; SANTOS, K. C.; PEREIRA, A. M.

No Maranhão, a expansão recente de áreas destinadas à silvicultura do eucalipto tem alterado os pequenos territórios agrícolas, modificando a estrutura da produção da agricultura de subsistência em pequenos municípios. Esse fenômeno também tem desencadeado a concentração de terra, a fragmentação do trabalho rural, além da diminuição da produção de culturas agrícolas historicamente importantes na região.

\section{A EXPANSÃO DA SILVICULTURA DO EUCALIPTO NO MARANHÃO E O USO DO TERRITÓRIO}

O eucalipto (Eucalyptus) é uma planta arbórea nativa da Oceania, descoberta pelos ingleses, na Austrália, em 1788. No entanto a disseminação de suas sementes pelo mundo começou apenas no início do século XIX. O eucalipto se apresenta como a matéria-prima mais importante para a produção de papel, carvão e móveis. De fácil adaptação, divide-se em mais de 600 espécies e tem sido amplamente utilizado na silvicultura (BOTELHO; ANDRADE, 2012).

No Brasil, foi introduzido em 1868, no Rio Grande do Sul, com o objetivo de suprir as necessidades de lenha, postes e dormentes das estradas de ferro; sua comercialização intensificou-se a partir do início do século XX. Nos últimos anos, o Brasil vem ganhando espaço no mercado internacional de produtos de origem florestal, e a produção de celulose vem apresentando grandes avanços, impulsionada pela ampla disponibilidade de terras e mão de obra barata (BOTELHO; ANDRADE, 2012).

No Maranhão, o uso da terra por essa atividade está diretamente vinculado aos processos de reestruturação produtiva baseados em grandes projetos agromineroexportadores, como o Projeto Grande Carajás. Esse projeto configurou um imenso corredor de exportação de minério de ferro e desencadeou a instalação de complexos siderúrgicos no estado, demandando a produção de lenha que serviria de fonte de energia para as indústrias (OLIVEIRA, 2019).

Dessa forma, os projetos de investimentos incentivados pelo Estado, melhor dizendo, financiados pela Superintendência do Desenvolvimento do Nordeste (Sudene) e pela Superintendência do Desenvolvimento da Amazônia (Sudam) favoreceram a expansão não só da sojicultura, mas também dos plantios de eucalipto para o abastecimento da produção siderúrgica. Como consequência, grandes quantidades de terras foram compradas por preços abaixo do mercado, intensificaram-se os processos de expropriação camponesa e de transformação das áreas de babaçuais em florestas plantadas (NOGUEIRA, 2019; BOTELHO; ALENCAR, 2019; PROTACIO, 2016).

Até o final da década de 1980, concentraram-se na cidade de Açailândia empresas do complexo de produção de ferro-gusa, aproveitando o incentivo para projetos dessa natureza, a proximidade com a matériaา-prima e com o porto para escoação da produção. A matriz energética foi fincada principalmente na utilização do extrativismo arbóreo de eucalipto para alimentação das caldeiras. É a partir daí que se instala a primeira base florestal de eucalipto no Maranhão (OLIVEIRA; LEAL, 2019).

A exemplo disso, na década de 1990, a então Companhia Vale do Rio Doce (CVRD) deu início ao primeiro Programa de Polos Florestais do estado, com um vasto plantio de áreas de eucalipto destinadas à produção de celulose no Maranhão, principalmente na área de influência da Estrada de Ferro Carajás. A Companhia de Celulose do Maranhão (Celmar), um dos empreendimentos aliados à CVRD e inseridos nesse programa, tinha como projeto inicial a instalação de uma planta industrial em Imperatriz, a partir do ano de 1996, com a finalidade de produzir celulose; esta teria a capacidade de produzir 420 mil toneladas ao ano em uma área de plantio de 180 mil hectares. No entanto, antes do início da construção da unidade fabril, em 1997, com a privatização da CVRD, a Celmar centralizou seus investimentos apenas no plantio de eucalipto para produção de carvão, combustível das siderúrgicas (NOGUEIRA, 2019; MATIAS, 1994). 
O carvão vegetal é um dos produtores energéticos mais importantes da indústria siderúrgica nacional e sua produção está estritamente ligada a essa indústria. No Maranhão, não só pela debilidade de infraestrutura energética na década de 1980, como pela própria redução de custos que o carvão vegetal proporciona, parte expressiva da retirada de madeira (seja eucalipto ou mata nativa) foi direcionada para essa atividade. A implantação da indústria de mineração e das siderúrgicas levou a uma expansão da silvicultura de eucalipto, o que abriu caminho para o extrativismo arbóreo intensificado a partir da reestruturação desencadeada pela implantação da Suzano Papel e Celulose, em Imperatriz, e sua cadeia produtiva (OLIVEIRA; NASCIMENTO, 2019; PEREIRA; CARVALHO, 2018).

Na Figura 1, apresenta-se a evolução da produção de carvão para atender aos complexos industriais de produção mineral do estado. Embora os dados oficiais não façam distinção entre o que é originário de eucalipto ou de mata nativa, parte expressiva do volume produzido e apresentado a seguir é oriundo de silvicultura plantada já existente.

Figura 1. Produção de carvão vegetal no Maranhão (1986-2018)

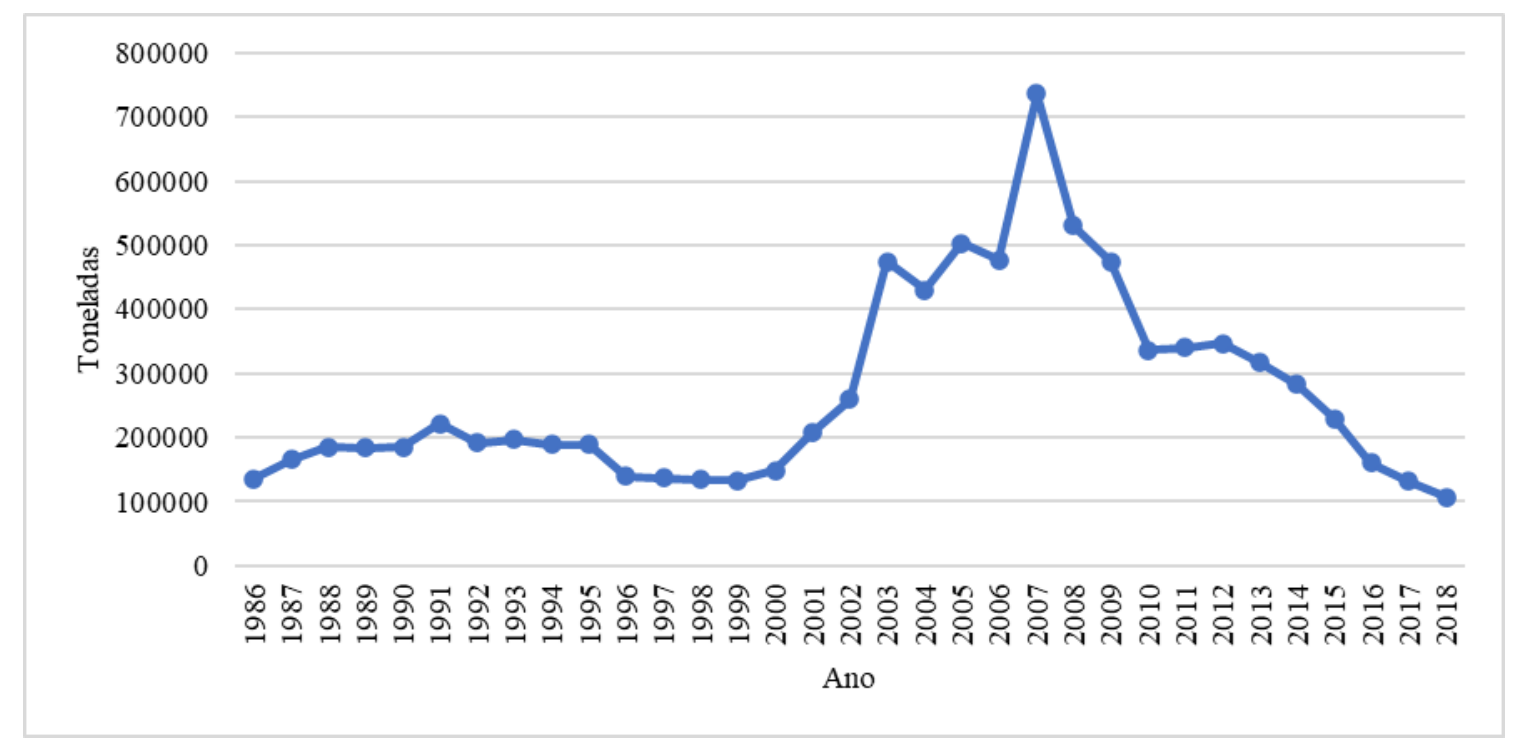

Fonte: Os autores (2020) a partir de dados do IBGE (2019a)

O pico da produção de carvão foi o ano de 2008, posteriormente entrando em declínio. A data coincide com dois eventos importantes: o primeiro trata do início da construção da fábrica da Suzano Papel e Celulose, que incorporou a expressiva base já plantada no estado, diminuindo, assim, a produção de carvão; o segundo diz respeito ao início da crise no setor produtor de ferro-gusa, que causou o fechamento de uma indústria em 2010 e outras duas em 2016.

Toda essa dinâmica criou a base para instalação da Suzano Papel e Celulose, em 2008. Seu funcionamento é resultado de intenso processo de territorialização de uso e ocupação da terra, de reestruturação do segmento de força de trabalho e dos meios de transporte (com incremento no quantitativo de caminhões para transportar eucalipto). Além disso, sua atuação levou a pasta de celulose a ser a segunda commodity mais expressiva do estado, perdendo apenas para a soja.

As formas de expansão da silvicultura do eucalipto refletem o modelo de desenvolvimento do modo capitalista de produção no Brasil, caracterizado pela fusão dos dois papéis, o do capitalista e o do proprietário de terra, em uma mesma pessoa. Essa união foi significativamente ampliada no século XX, conforme explica Oliveira (1993): 
OLIVEIRA, A. B.; SANTOS, K. C.; PEREIRA, A. M.

A política de incentivos fiscais da Sudene e da Sudam foram os instrumentos de política econômica que viabilizaram esta fusão. Dessa forma, os capitalistas urbanos tornaram-se os maiores proprietários de terra no Brasil, possuindo áreas com dimensões nunca registradas na história da humanidade. (OLIVEIRA, 1993, p. 186).

Essa conjuntura política permeou a implantação de complexos em moldes correspondentes à economia de enclave, caracterizada como um sistema econômico voltado para a produção de commodities de exportação e cujos benefícios não atingem a maioria dos segmentos sociais. Um exemplo disso é o desenvolvimento do agronegócio, representado pelo plantio extensivo de soja e eucalipto, cultivos que se consolidaram e expandiram as fronteiras econômicas do Maranhão (MESQUITA et al, 2015).

Diante disso, a Figura 2 apresenta dados da expansão da silvicultura de eucalipto no Maranhão, no período de 2005 a 2018, e revela muito claramente um aumento das áreas destinadas a esse plantio, sobretudo a partir do início das atividades da unidade fabril da Suzano, em 2013. Atualmente a produção de eucalipto para pasta de celulose é umas das principais atividades desenvolvidas no estado, sendo voltada para o capital internacional.

Figura 2. Expansão da silvicultura de eucalipto no Maranhão

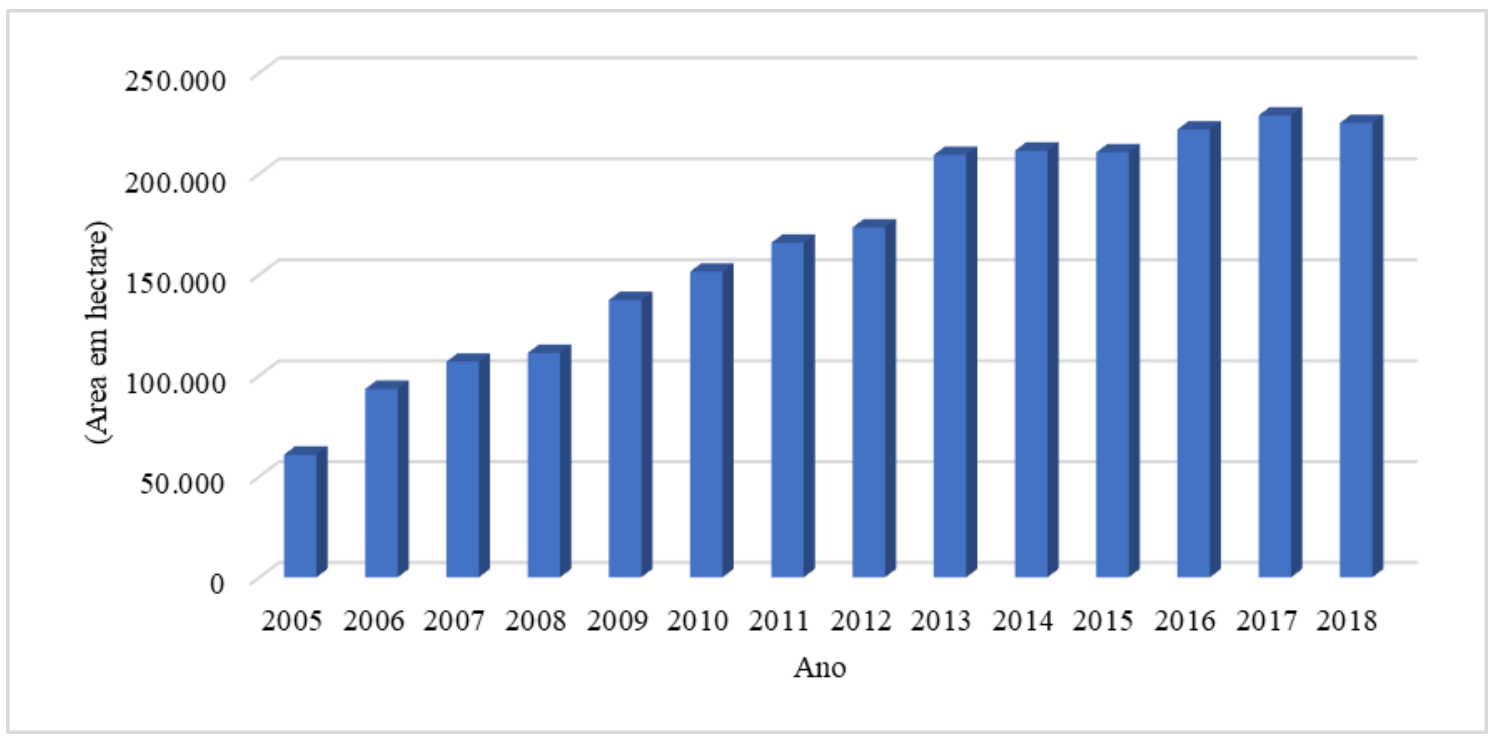

Fonte: Os autores (2020), com base em dados da Indústria Brasileira de Árvores (IBÁ, 2019)

Como mostra a Figura 2, a área de produção de eucalipto teve um aumento de aproximadamente $270 \%$ no estado, entre 2005 e 2018, sendo que a partir de 2013, o aumento foi em torno de $7 \%$, representando um acréscimo de cerca de 35 mil hectares. Especificamente os dados relativos ao volume de áreas plantadas nos municípios de Davinópolis, Governador Edison Lobão e Ribamar Fiquene são apresentados na Figura 3, que evidencia o aumento significativo das áreas destinadas ao plantio de eucalipto nos municípios estudados entre os anos de 2013 e 2019.

Nesse período, o cultivo de eucalipto em Davinópolis apresentou um crescimento gradual em relação aos demais municípios, o que pode ser explicado pelo fato de esse município já ter um histórico de produção de eucalipto desde a época de atuação da CVRD, com o projeto Celmar. Naquele momento, a produção tinha como foco o carvão vegetal. Em 2013, a área de plantio de 
OLIVEIRA, A. B.; SANTOS, K. C.; PEREIRA, A. M.
OS NOVOS USOS DO TERRITÓRIO PELO AGRONEGÓCIO FLORESTAL NA MICRORREGIÃO DE IMPERATRIZ, MARANHÃO

eucalipto era de cerca de 800 hectares, crescendo $16 \%$ até o ano de 2019.

Ainda considerando o processo de implantação fabril da Suzano (entre 2008 e 2013), observa-se que, nos municípios de Governador Edison Lobão e Ribamar Fiquene, o crescimento das áreas de cultivo de eucalipto coincide com o desenvolvimento da cadeia de papel e celulose, indicado pela expansão de áreas plantadas a partir de 2013, ano de início das atividades da fábrica. O município de Governador Edison Lobão registrou um aumento de $90 \%$ em sua área plantada; em Ribamar Fiquene, o aumento foi de 39\%, comparando o período de 2013 a 2018.

Figura 3. Expansão da área de cultivo de eucalipto no sul da microrregião de Imperatriz

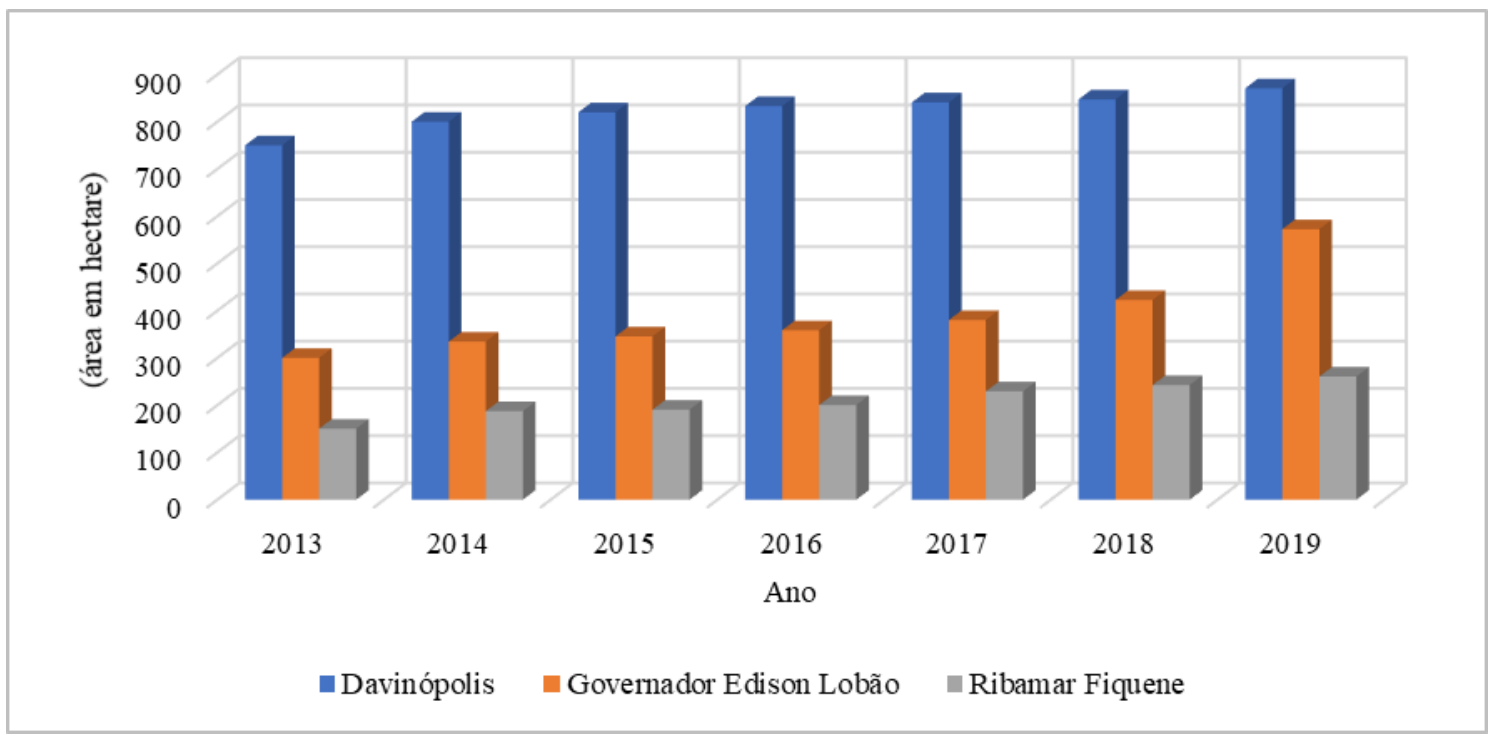

Fonte: Os autores (2020) a partir de dados do IBGE (2019a)

O processo de territorialização e novos usos da terra pelo cultivo dominante do eucalipto pode ser percebido observando-se a grande concentração de terras da Suzano. Esse acúmulo fundiário advém das terras outrora pertencentes à CVRD (com o projeto Celmar) e das indústrias produtoras de ferro-gusa, além de terras oriundas de compra e arrendamento. Essa configuração territorial transformou as relações no campo e reestruturou os usos da terra à medida que novas dinâmicas políticas também emergiram nesse cenário. Formas de trabalho, características e objetivos novos são demonstrados em marcações bem claras, percebidas em placas (Figura 4), caminhões, tratores e novos perfis de trabalhador. Os fluxos tradicionais do campo assumem outras formas, funcionalidades e um tempo bem mais rápido.

Ocorre, desta forma, uma rápida transição dos antigos para os novos usos da terra. As atividades tradicionais, como campesinato, agricultura de subsistência, pequenas criações de animais e as formas de trabalho ligadas a elas dão lugar à monocultura de eucalipto (Figura 5). Essa reestruturação é herança de uma fronteira agrícola que data dos anos 1980, altamente mecanizada, entrelaçada com grandes projetos e subordinada ao grande capital exportador, que agora dita a lógica predominante.

Na Figura 5, percebe-se mais claramente os processos aqui discutidos, na medida em que se visualiza a ampla reconfiguração de territórios agrícolas em prol do eucalipto. Desta forma, observa-se que há um forte avanço do eucalipto não só sobre áreas destinadas à agricultura familiar, mas também unidades de conservação, áreas de proteção permanente, áreas de assentamento, além de terras indígenas. 
OLIVEIRA, A. B.; SANTOS, K. C.; PEREIRA, A. M.
OS NOVOS USOS DO TERRITÓRIO PELO AGRONEGÓCIO FLORESTAL NA MICRORREGIÃO DE IMPERATRIZ, MARANHÃO

Nos municípios estudados (Davinópolis, Governador Edison Lobão e Ribamar Fiquene), o maior agravante é o avanço do eucalipto em direção a assentamentos e áreas de agricultura familiar que, historicamente, fornecem alimentos básicos para vilarejos e municípios vizinhos

Figura 4. Demarcação territorial de fazendas de eucalipto
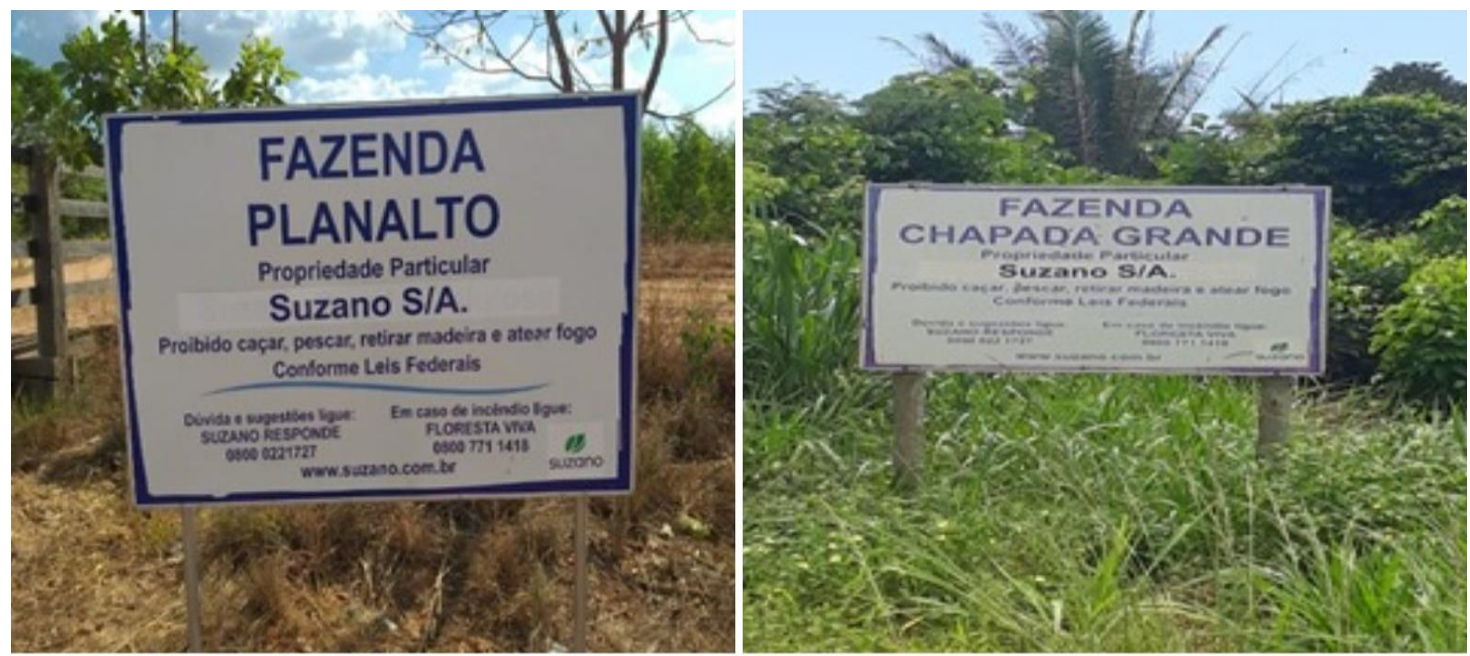

Fonte: Os autores (2019)

Figura 5. Monocultura do eucalipto na microrregião de Imperatriz - MA
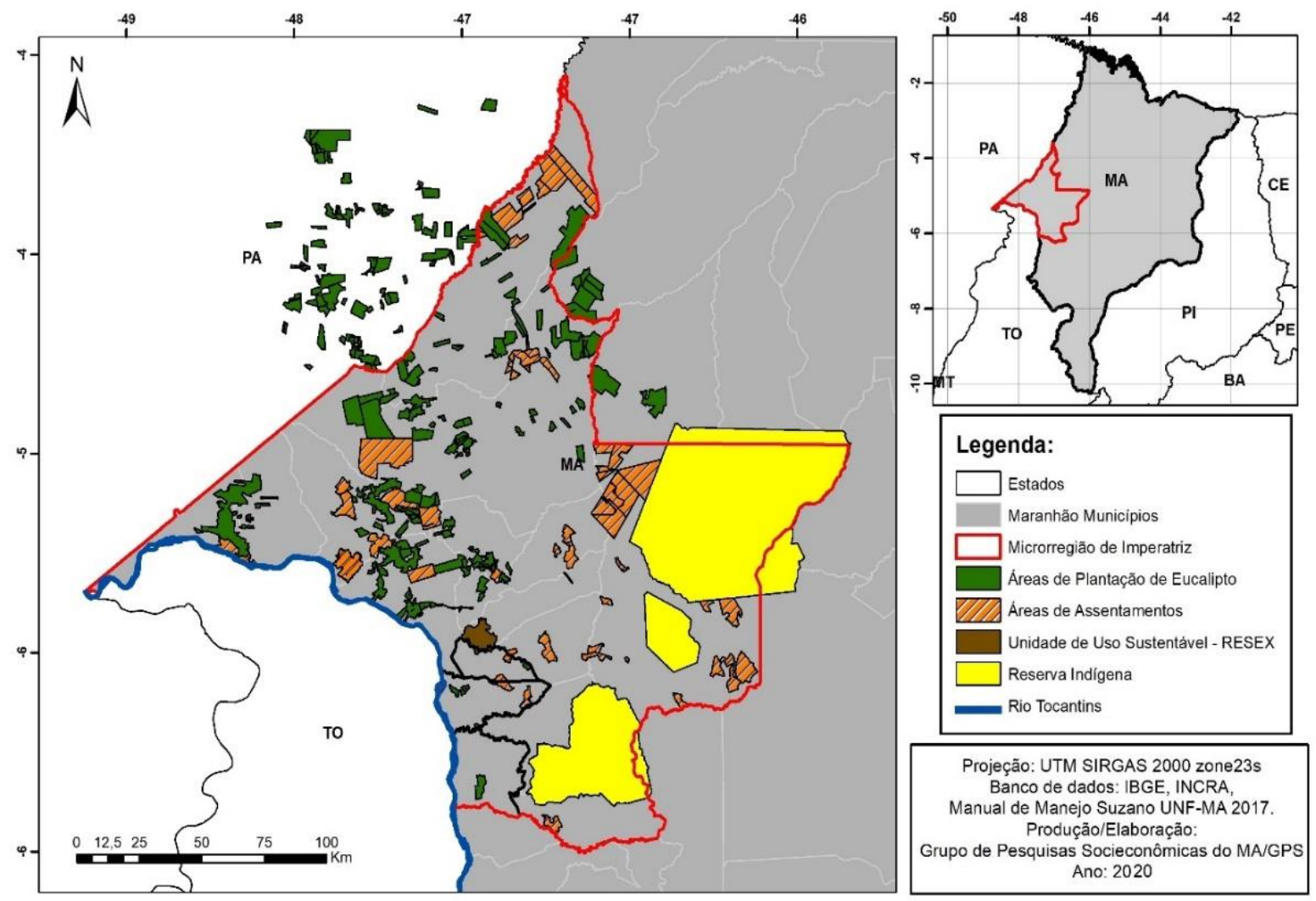

Fonte: Os autores (2020) 


\section{TRANSFORMAÇÕES DAS ATIVIDADES AGRÍCOLAS TRADICIONAIS EM MUNICÍPIOS MARANHENSES}

Segundo Oliveira (2019), o modelo de produção maranhense vem sofrendo transformações nos últimos anos, principalmente nas relações com o uso da terra, tendo em vista que a terra está inserida em um processo de reestruturação produtiva e de novos usos do território. Uma vez que a produção de commodities exige mais espaço, a expansão dos grandes empreendimentos principalmente a partir da década de 1980 - amplia a ocorrência de conflitos agrários, sobretudo entre camponeses, assentados e empresários,

A economia camponesa baseia-se na produção agrícola de subsistência. No sul da microrregião de Imperatriz, essa atividade se caracteriza pela apropriação e manejo de diferentes culturas para a manutenção de pequenos grupos familiares. Além disso, a produção também é comercializada em pequenas feiras de comunidades circunvizinhas. Nesse contexto, percebe-se que a inserção da silvicultura do eucalipto na região promove transformações na relação dos trabalhadores rurais com os recursos naturais, como é característico do avanço do capitalismo no campo.

Nas zonas rurais dos municípios estudados, existem comunidades e áreas de assentamento que mantêm trabalho familiar e policultura baseada em subsistência; são proprietários de pequenas extensões de terras, que também criam alguns animais para o próprio sustento. As comunidades tradicionais vivem em organização social sem força de trabalho assalariado, com a população vinculada a pequenas atividades econômicas, como: agricultura, pesca e artesanato. Destaca-se que a silvicultura de eucalipto tem uma parcela significativa de responsabilidade na desarticulação dessa realidade, visto seus efeitos negativos sobre as comunidades rurais.

No município de Davinópolis, que apresentou o maior índice de crescimento das áreas destinadas ao cultivo de eucalipto, observa-se, no período de 2008 a 2018, o declínio na produção das culturas tradicionais de arroz, mandioca e feijão. Ao longo dos anos, houve uma queda significativa na área plantada de arroz: passou de cerca de 700 hectares de área plantada, em 2008, para menos de 100 hectares, em 2018, resultando em uma queda de aproximadamente $97 \%$. O mesmo ocorreu com a produção de mandioca, que registrou uma diminuição de $57 \%$ na área de cultivo; e de feijão, com aproximadamente $48 \%$ de redução.

Figura 6. Produção agrícola no município de Davinópolis (2008-2018)

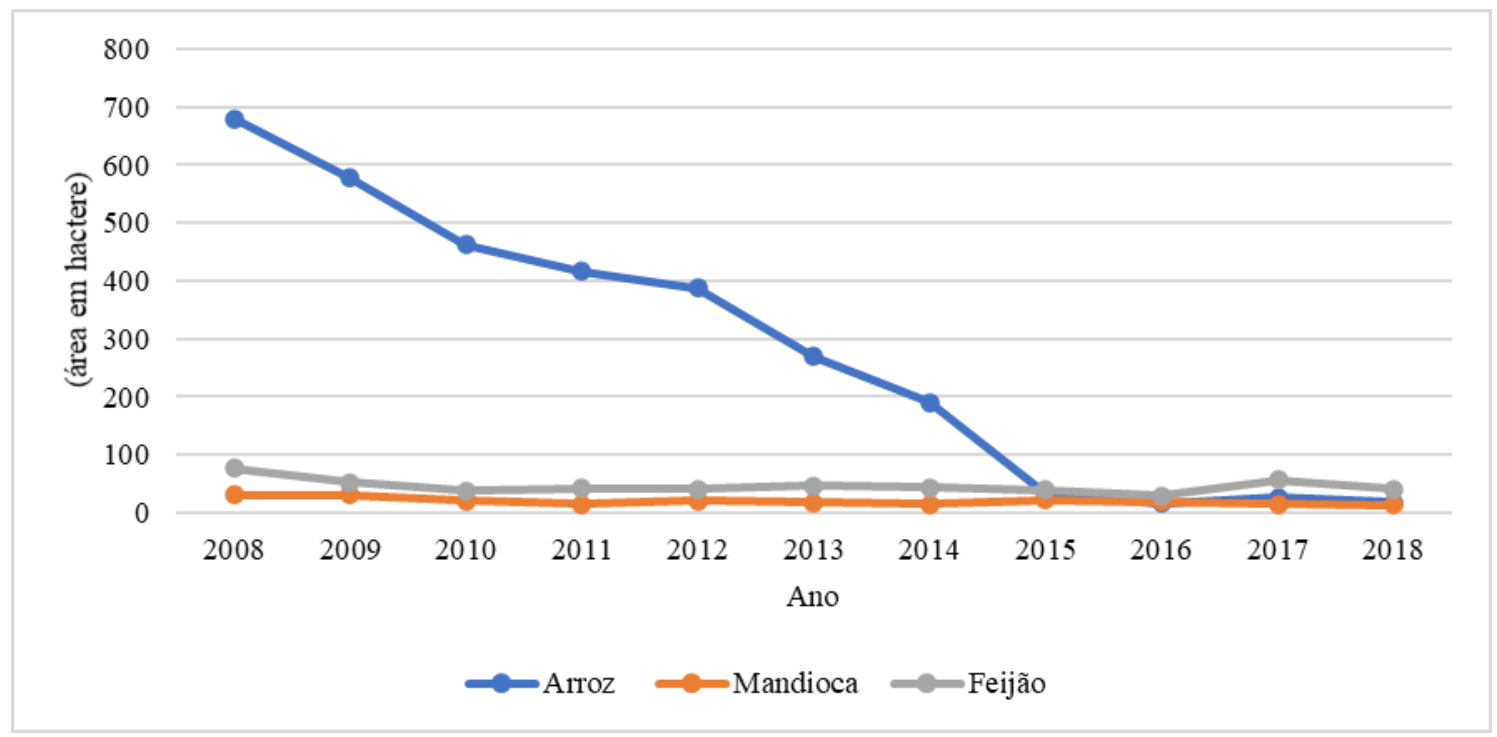

Fonte: Organizado pelos autores (2020) a partir de dados do IBGE (2019b) 
OLIVEIRA, A. B.; SANTOS, K. C.; PEREIRA, A. M.
OS NOVOS USOS DO TERRITÓRIO PELO AGRONEGÓCIO FLORESTAL NA MICRORREGIÃO DE IMPERATRIZ, MARANHÃO

Embora não se possa ainda considerar essas transformações como resultantes exclusivamente da expansão da silvicultura (outras transformações no campo brasileiro vêm se acentuando nas duas últimas décadas), a diminuição gradual de áreas destinadas a culturas tradicionais, como o arroz, ocorre justamente no momento de maior avanço da silvicultura do eucalipto no estado.

Assim, os dados também indicam uma relação entre a diminuição das atividades tradicionais e a ascensão da territorialização dos monopólios, que "atuam simultaneamente, no controle da propriedade privada da terra, do processo produtivo no campo e do processamento industrial da produção agropecuária" (OLIVEIRA, 2010, p. 26). Portanto, o decréscimo dessas atividades e, consequentemente, a diminuição das áreas a elas destinadas ocorre à medida que se fortalece $\mathrm{o}$ controle das grandes empresas sobre o território.

Essas transformações no uso da terra também modificam as relações laborais, visto que a monocultura de eucalipto demanda pouca e variável força de trabalho. Explica-se a reduzida capacidade de absorção da mão de obra devido ao fato de que o avanço do capital no campo ocorre juntamente com a modernização tecnológica. Enquanto se ampliam a incorporação e o acúmulo de extensões de terra, o uso da força de trabalho no campo segue um outro ritmo: o da desaceleração (ESKINAZI; SOUZA, 2013; TOLEDO, 2012).

Neste contexto, as comunidades que se encontram próximas às fazendas de eucalipto da Suzano Papel e Celulose recebem da empresa os chamados campos agrícolas. Mais especificamente no povoado de Varjão do Crentes - situado no município de Buritirana, fronteira com Davinópolis —, a empresa firmou uma parceria com a associação de moradores locais e disponibilizou para a comunidade um campo agrícola dentro de sua fazenda. No local, cerca de 28 famílias produzem em uma área de 40 hectares, com assistência técnica da Suzano para os produtores. Dentre os produtos agrícolas mais cultivados estão: milho; feijão; mandioca, para a produção de farinha; e arroz, para a subsistência e venda na comunidade local (Figura 7).

Figura 7. Terra mecanizada para o plantio de culturas tradicionais, em Davinópolis
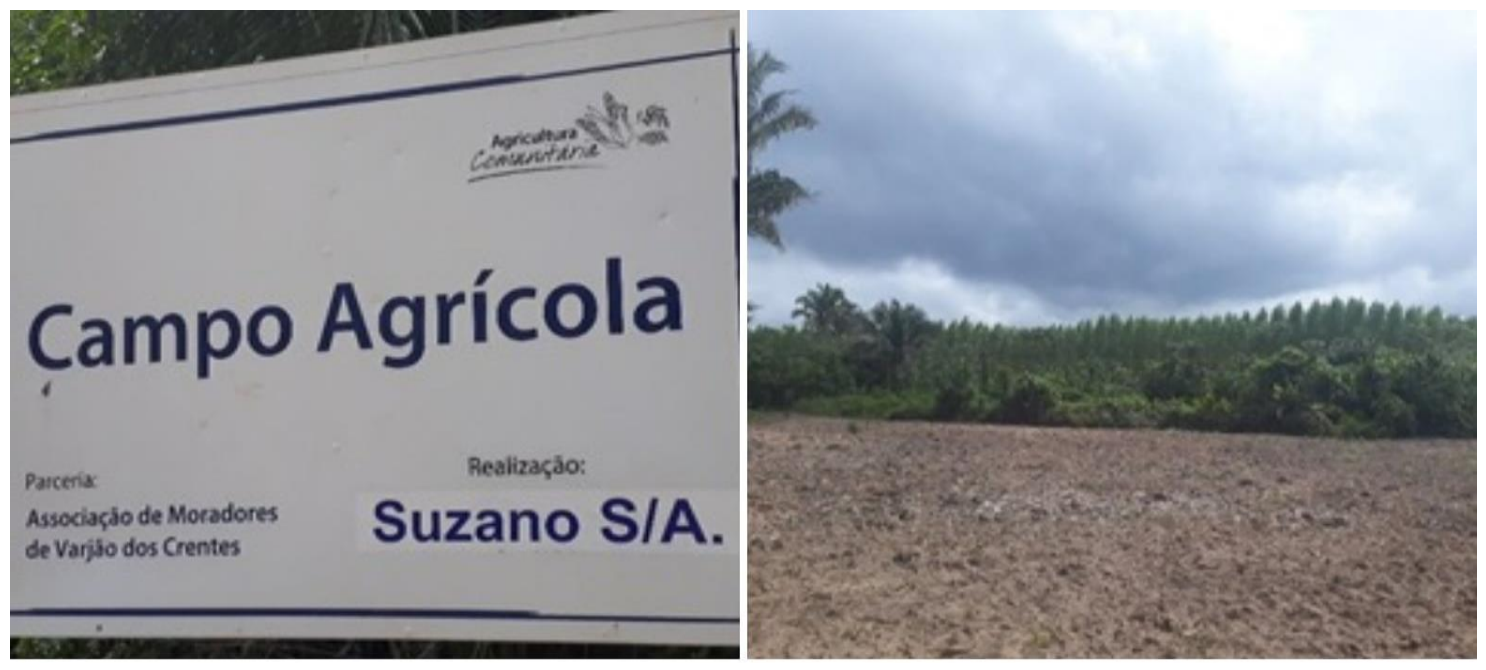

Fonte: Os autores (2019)

No entanto, as relações de trabalhos ali estabelecidas, constantemente, são alvo de críticas do assentamento Juçara, situado em Davinópolis. A população se queixa da falta de assistência da empresa, dos danos causados na estrada pelos caminhões que fazem o manejo do eucalipto e ainda do desgaste dos recursos hídricos da região. Isso porque a monocultura de eucalipto também modifica os regimes do ciclo hidrológico, causando seca em córregos e poços no 
OLIVEIRA, A. B.; SANTOS, K. C.; PEREIRA, A. M.
OS NOVOS USOS DO TERRITÓRIO PELO AGRONEGÓCIO FLORESTAL NA MICRORREGIÃO DE IMPERATRIZ, MARANHÃO

entorno das monoculturas, como é o caso do riacho Cacau (Figura 8), um importante riacho para o abastecimento de água a ser usada na agricultura e pecuária. Além disso, a pesca na região também tem diminuído gradativamente nos últimos anos.

Figura 8. Riacho Cacau, no município de Davinópolis
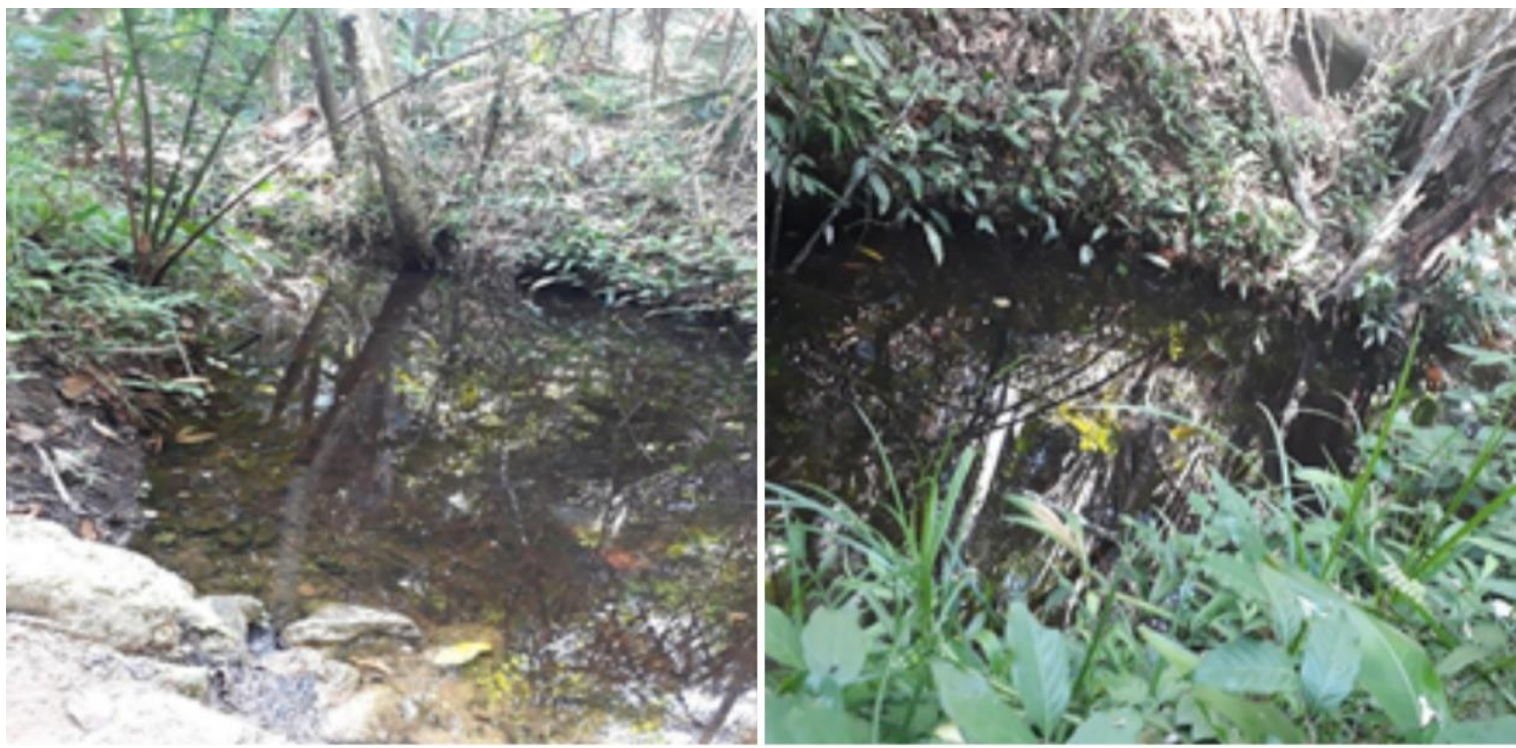

Fonte: Os autores (2019)

No município de Governador Edison Lobão, as transformações na estrutura produtiva da agricultura também são evidentes, visto que percorrem a mesma trajetória imposta pelo avanço do capital no campo. Na Figura 9, observa-se que, no período de 2008 a 2018, houve uma queda significativa no volume de área plantada das três principais culturas tradicionais: arroz, mandioca e feijão. Em 2008, o município apresentava uma área de cerca de 350 hectares plantados de arroz. Dois anos depois, em 2010, esse número caiu para 200 hectares, passando para menos de 100 hectares em 2015, representando uma queda próxima de 95\% em dez anos.

O mesmo ocorre com o cultivo da mandioca que, apesar de não ser uma atividade essencial da região, era praticada na fazenda que hoje é utilizada para produzir eucalipto. A produção de mandioca caiu cerca de $10 \%$, enquanto a de feijão, também um cultivo comum entre camponeses, foi reduzida à metade, uma queda de $49 \%$ entre 2008 e 2018.

No município de Ribamar Fiquene, a dinâmica de apropriação do espaço para a produção de eucalipto se dá por meio do processo de arrendamento. Nesse local, a fazenda analisada foi arrendada no ano de 2013, e atualmente está no segundo ciclo de produção. De 2.400 hectares, apenas 250 são destinados para o plantio de eucalipto, o excedente é destinado para a criação de gado, plantação de melancia e milho. Nas terras onde não se pratica exclusivamente a monocultura, mantém-se uma relação entre as atividades tradicionais e as de silvipastoril, predominantes nessa propriedade. Contudo, a produção de culturas tradicionais no município, de acordo com os dados do IBGE (2019b), está em declínio desde 2008. 
Figura 9. Produção agrícola no município de Governador Edison Lobão (2008-2018)

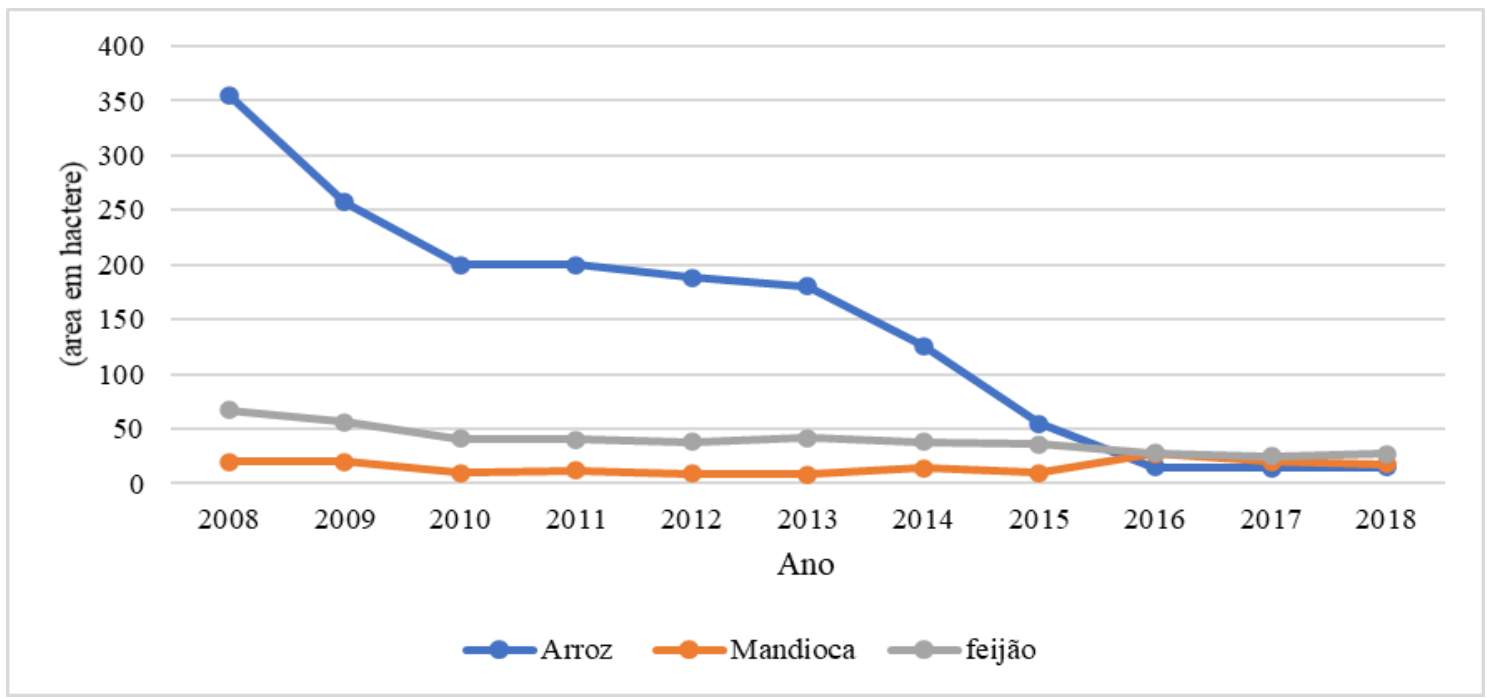

Fonte: Organizado pelos autores (2020) a partir de dados do IBGE (2019b)

A produção de arroz, por exemplo, teve um aumento no ano de 2008; a área dessa plantação passou de 500 para 700 hectares em 2010, permanecendo a mesma no ano seguinte. Já a partir de 2012, houve um declínio expressivo na produção, diminuindo cerca de $70 \%$. De forma semelhante, as produções de mandioca e feijão também tiveram uma diminuição significativa, no entanto, só a partir de 2015, dois anos após a instalação da unidade fabril da Suzano, é que se agravou ainda mais a diminuição da área plantada, como mostra a Figura 10.

Figura 10. Produção agrícola no município de Ribamar Fiquene (2008-2018)

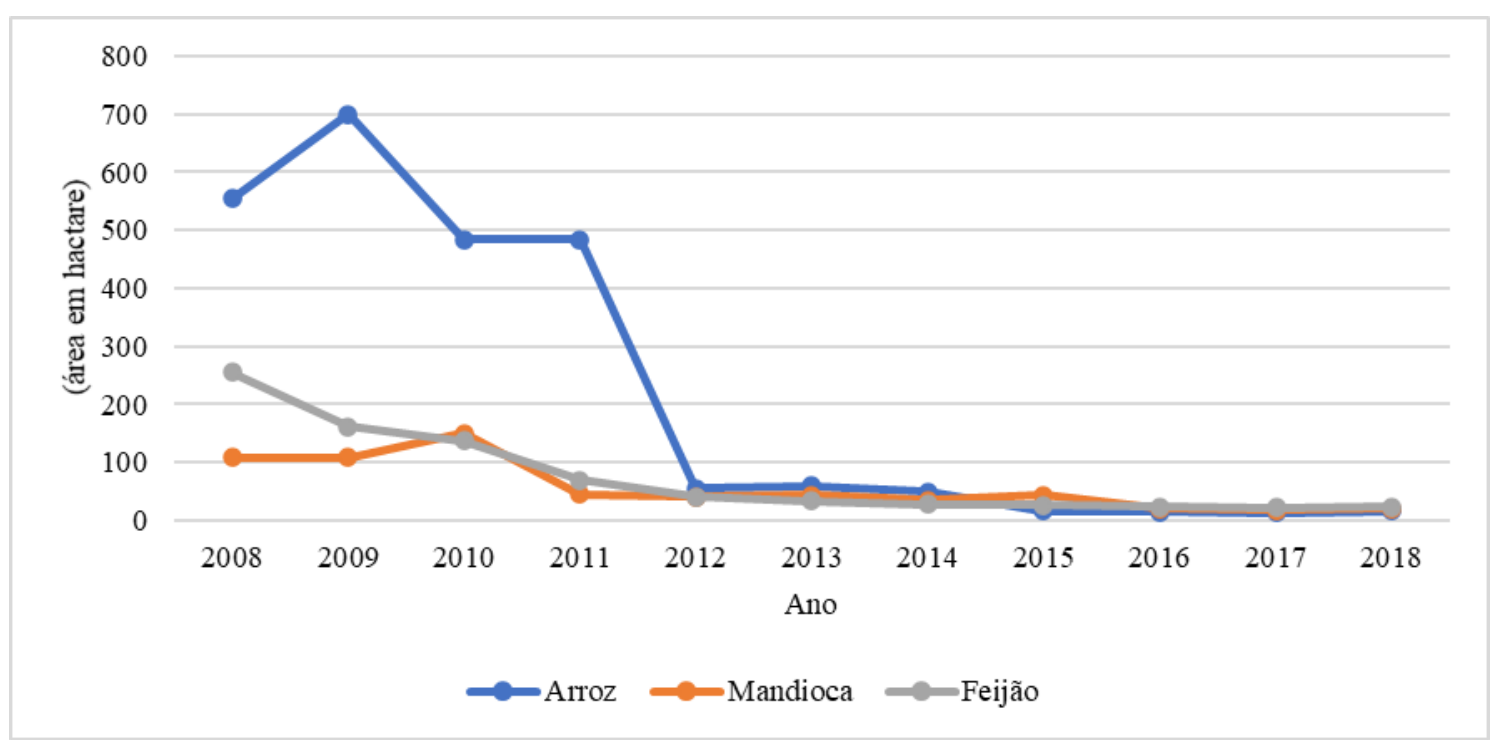

Fonte: Organizado pelos autores (2020) a partir de dados do IBGE (2019b)

Dessa forma, fica expresso que nos últimos anos houve transformações no uso da terra, bem como do território do espaço rural maranhense, uma vez que as atividades agroflorestais do eucalipto vêm se expandindo e se apropriando do espaço antes destinado à produção de culturas agrícolas, como é o caso do sul da microrregião de Imperatriz. As atividades agrícolas 
tradicionais dessa região estão cada vez mais reduzidas, pois os pequenos produtores rurais são empurrados para as margens das novas relações impostas pelo mercado globalizado. Nesse contexto, passam a depender da produção para o mercado interno e das ofertas de trabalho assalariado nas grandes propriedades privadas.

\section{CONSIDERAÇÕES FINAIS}

A monocultura de eucalipto no Brasil representa um modelo predatório e intensificador de conflitos agrários. A silvicultura, em específico, não extinguiu em sua totalidade os pequenos trabalhadores, por isso não se pode afirmar que a sua expansão é a única responsável pelos problemas aqui apresentados. Entretanto, contribuiu para a diminuição de áreas destinadas a atividades tradicionais de produção alimentar, essenciais à subsistência das comunidades locais que vivem às margens das áreas de plantio.

A especulação fundiária, aliada aos impactos ambientais, tem gerado incertezas para os grupos de agricultura familiar, contribuindo para o crescente aumento de fluxos de trabalhadores do campo em direção às cidades em busca de melhores condições de vida. Esses elementos interferem diretamente na diminuição de áreas de plantios tradicionais, impactando na produção de culturas como: arroz, mandioca e feijão.

\section{AGRADECIMENTOS}

Este trabalho é resultado de pesquisa desenvolvida com auxílio financeiro concedido pela Fundação de Amparo à Pesquisa e ao Desenvolvimento Científico e Tecnológico do Maranhão (FAPEMA).

\section{REFERÊNCIAS}

AZEVEDO, M. P. Os ciclos econômicos do Maranhão: do algodão ao mínero-metalúrgico. 2003. Dissertação (Mestrado em Economia) - Universidade Federal de Pernambuco, Recife, 2003. Disponível em: https://bit.ly/3emXIpa. Acesso em: 26 maio 2020.

BOTELHO, A. C.; ALENCAR, F. A. Resistência nas chapadas do Baixo Parnaíba: conflitos de lógicas entre a silvicultura e os camponeses do povoado Todos os Santos em Urbano Santos - Maranhão. Geosul, Florianópolis, v. 34, n. 71, p. 550-572, abr. 2019. Dossiê Agronegócios no Brasil. Disponível em: https://bit.ly/2LXmUqa. Acesso em: 26 maio 2020.

BOTELHO. A. C.; ANDRADE. M. P. A expansão da silvicultura: impactos socioambientais em territórios camponeses no leste maranhense. Uberlândia, 2012. In: ENCONTRO NACIONAL DE GEOGRAFIA AGRÁRIA, 21., 2012, Uberlândia. Anais eletrônicos [...]. Uberlândia: UFU, 2012. Disponível em: https://bit.ly/2zqIK2S. Acesso em: 26 maio 2020.

CHAMBOULEYRON, R. Povoamento, ocupação e agricultura na Amazônia Colonial (1640-1706). Belém: Editora Açaí, 2010.

HAESBAERT, R. Território e multiterritorialidade: um debate. In: VASCONCELOS JÚNIOR et al (org.). Multiterritorialidades e novas práticas culturais. Fortaleza: RDS, 2012. p. 11-52.

HAESBAERT, R. Des-territorialização e identidade: a rede "gaúcha" no Nordeste. Niterói: EDUFF, 1997.

ESKINAZI, B. G; SOUZA, J. G. Especialização produtiva e homogeneização territorial: a monocultura de eucalipto no Vale do Paraíba paulista e as transformações nas dinâmicas de produção. Revista Pegada, Presidente Prudente, v. 14, n. 2, p. 194-211, dez. 2013. 
OLIVEIRA, A. B.; SANTOS, K. C.; PEREIRA, A. M
OS NOVOS USOS DO TERRITÓRIO PELO AGRONEGÓCIO FLORESTAL NA MICRORREGIÃO DE IMPERATRIZ, MARANHÃO

IBGE. Produção extrativista e da silvicultura no Brasil. Rio de Janeiro: IBGE, 2019a. Disponível em: https://www.ibge.gov.br/. Acesso em: 9 jan. 2020.

IBGE. Sistema IBGE de Recuperação Automática - SIDRA. Levantamento sistemático da produção agrícola 2008/2018. Rio de Janeiro: IBGE, 2019b. Disponível em: https://www.ibge.gov.br/. Acesso em: 9 jan. 2020.

INDÚSTRIA BRASILEIRA DE ÁRVORES. Relatório de produção da silvicultura no Brasil. Brasília: IBÁ, 2019. Disponível em: https://www.iba.org/. Acesso em: 9 jan. 2020.

MATIAS, M. A implantação da indústria de celulose no Maranhão: Celmar na região Tocantina. Belém: Seminário Consulta Carajás, 1994. (Cartilha n. 3).

MESQUITA, B. A. et al. Formação socioeconômica do estado do Maranhão. In: CASTRO, E. R.; CAMPOS, I. (org.). Formação socioeconômica da Amazônia. Belém: NAEA/UFPA, 2015. p. 225-319.

NOGUEIRA, A. P. F. As políticas de desenvolvimento hegemônico como base para a reestruturação produtiva na Estrada do Arroz, Imperatriz-MA. In: ENCONTRO NACIONAL DA ANPEGE, 13., 2019, São Paulo. Anais eletrônicos [...]. São Paulo: Anpege, 2019. Disponível em: https://bit.ly/2WFvzDV. Acesso em: 26 maio 2020.

OLIVEIRA, A. B. Indústria de celulose e o avanço da silvicultura do eucalipto na fronteira agrícola da Amazônia maranhense. Geosul, Florianópolis, v. 34, n. 71, p. 301-327, abr. 2019. Dossiê Agronegócios no Brasil. Disponível em: https://bit.ly/2XacWXE. Acesso em: 26 maio 2020.

OLIVEIRA, A. B; LEAL. M. C. M. Silvicultura do eucalipto e a especialização do trabalho na cadeia produtiva de papel e celulose em Imperatriz-MA. GeoTextos, Salvador, v. 15, n. 2, p. 87-108, dez. 2019. Disponível em: https://bit.ly/3d61l5k. Acesso em: 26 maio 2020.

OLIVEIRA, A. B; NASCIMENTO, D. M. Redes e mobilidade do capital na cadeia produtiva de papel e celulose no Maranhão. Geographia Opportuno Tempore, Londrina, v. 5, n. 1, p. 52-66, 2019. Acesso em: https://bit.ly/3c4ePe1. Disponível em: 26 maio 2020.

OLIVEIRA, A. U. A questão da aquisição de terras por estrangeiros no Brasil - um retorno aos dossiês. Agrária, São Paulo, n. 12, p. 3-113, 2010. Disponível em: https://bit.ly/3eo2UcA. Acesso em: 26 maio 2020.

OLIVEIRA, F. Elegia para uma re(li)gião: Sudene, Nordeste. Planejamento e conflito de classes. Rio de Janeiro: Paz e Terra, 1993.

PEREIRA, J. M; CARVALHO, A. C. Motosserras e máquinas no Maranhão pré-amazônico: reestruturação produtiva e os trabalhadores do corte do eucalipto. Revista Org \& Demo, Marília, v. 19, n. 1, p. 113-130, jan./jun. 2018. Disponível em: https://bit.ly/3egpio2. Acesso em 26 maio 2020.

PROTACIO, A. P. B. Entre a enxada e o papel: impactos socioambientais de atividades de produção de eucaliptos nas comunidades de pequenos produtores no município de Urbano Santos. 2016. Trabalho de Conclusão de Curso (Licenciatura em História) - Universidade Estadual do Maranhão, São Luís, 2016. Disponível em: https://bit.ly/2LYcqXC. Acesso em: 26 maio 2020.

SAQUET, M. A. Abordagens e concepções de territórios. São Paulo: Expressão Popular, 2007.

SILVA, J. M. Agricultura familiar e territorialidade: as comunidades Cruzeiro dos Martírios e Paulistas no município de Catalão (GO). 2011. Dissertação (Mestrado em Geografia) - Universidade Federal de Goiás, Catalão, 2011. Disponível em: https://bit.ly/3c499kd. Acesso em: 26 maio 2020.

SILVA, S. E. V. A agricultura familiar no Brasil e as transformações no campo no início do século XXI. 2010. Dissertação (Mestrado em Serviço social) - Universidade Federal de Alagoas, Maceió, 2010. Disponível em: https://bit.ly/2M0599V. Acesso em: 26 maio 2020.

SILVA, J. M; MENDES, E. P. P. Agricultura familiar e cultura: identidades e territorialidades. In: ENCONTRO NACIONAL DOS GEÓGRAFOS, 16., 2010, Porto Alegre. Anais [...]. Porto Alegre: ANG, 2010. 
OLIVEIRA, A. B.; SANTOS, K. C.; PEREIRA, A. M.
OS NOVOS USOS DO TERRITÓRIO PELO AGRONEGÓCIO FLORESTAL

NA MICRORREGIÃO DE IMPERATRIZ, MARANHÃO

TOLEDO, M. H. S. O impacto da plantação extensiva de eucalipto nas culturas tradicionais: estudo de caso de São Luís do Paraitinga-SP. Cadernos IHU ideias, São Leopoldo, ano 10, n. 167, 2012. Disponível em: https://bit.ly/2A7AkNQ. Acesso em: 26 maio 2020. 